Watch heard at two inches from the ear. A fleshy-looking polypus filled up the meatus. It was removed, and he was under treatment till August 17th, when a second small polypus appeared within the tympanum. This was taken away, and he attended once a week till Sept. 29th, the discharge having ceased, and the watch being heard at eight feet, and conversation very well. In this case, too, the membrane on the other side was perforated, but the hearing did not improve under treatment.

CASE 3. - April 19th, 1870. C. F. P_, male, aged eighteen. Discharge from right ear from a child. A large polypus projecting from the external meatus. Watch not heard on contact. He attended, after the polypus was removed, three times a week till May 10th; after then, sometimes once and at others twice a week till June 27th; from that date, occasionally at intervals of five or six weeks for six months. The perforation was very small, and the cavity of the tympanum became filled with discharge and made him deaf for the time; this caused the case to be so tedious. When dismissed he could hear conversation very well.

CASE 4. - M. M- female, aged twenty-two. After scarlet fever. A perforation, and a polypus filling the meatus on the right side. Watch not heard on contact. Polypus remored. She attended once a week for fourteen weeks, when she was dismissed, the discharge having ceased. Although she heard the watch at five feet, the improvement for conversation was not proportionately increased.

CASE 5.-W. H-, male, aged nineteen. A perforation and polypus after five years of discharge from the right ear. Watch heard on close contact. Attended twice a week for two months, and was dismissed, the discharge having ceased, and hearing increased to six feet with the watch, and conversation very well.

When a polypus grows from the meatus without a perforation of the membrane (a rare state of things), it is just as easy to prevent its regrowth as it is difficult when it arises from the tympanic cavity with a perforation. This occurred in

CASE 6, where Mr. T-, aged twenty-six, who could hear well four weeks before I saw him, could then only hear a watch at one inch from the ear, and had a polypus growing from the meatus, and blocking up the orifice. The polypus was removed, and showed no disposition to grow again, the temporary deafness being only due to closure of the meatus. In ten days no traces of it were to be seen. The membrane was quite healthy.

CASE 7.-E. L-, aged twenty-six. After catarrh of the tympanum without a perforation of the membrane. In this example a small polypus could be seen in close apposition to the membrane, and arising from the meatus. This was taken away. Caustic applied five times, and the growth was quite eradicated. The hearing, however, did not improve, the deafness depending on the condition of the cavity of the tympanum remaining after the catarrh.

Grosvenor-street, November, 1871.

\section{THE DANGER OF ILT_CONSTRUCTED AND NEGLECTED CISTERNS.}

BY J. JARDINE MURRAY, F.R.C.S.E.,

SURGEON TO THE BRIGHTON AND SUSSEX EYE INPTRMARY, AND PRESIDENT OF THE BRIGHTOY AND SUSSEX MEDICO-CHIRUBGICAL SOCIETY.

SEVERAL years ago I directed attention to the special dangers of ill-constructed and neglected cisterns, such as are met with in many of the houses in Brighton and other towns and villages throughout the country. Recent researches on the causes of epidemic diseases render this subject more important than ever, from a sanitary point of view.* But, as a rule, the cisterns in our $d w e l l i n g s$ are

* As far as regards the subject of this paper it matters not whether we aceept the "germ" or "vital" theory of Pasteur, or prefer the physicochemical doctrines of Liebig; whether we believe that diseases are alway caused and propagated by the presenee and self-multiplication of living units, or that they are sometimes also solely due to chemico-physica agencies. But, in its bearings on the practice of medicine and surgery, this is perhaps the most important question of the day, and the one which s being most keenly investigated and discussed.- Vide Professor Lister's
MIonographs on Antiseptic Surgery, and especially his Address at the Monographs on Antiseptic Surgery, and especially his Address at the
meeting of the British Medical Association in 1871; Professor Tyndall's as ill-constructed and neglected as formerly ; and, in newlybuilt houses, the faults appear to be just as bad-doubtless from ignorance, which in sanitary matters is more dangerous than wickedness.

In a house of small or moderate size there is usually only one cistern, from which water is drawn for drinking, cooking, and supplying the closets. The pipe which supplies a watercloset is often made to open by a tap at the end furthest from the cistern; but in many instances it will be found that water is admitted into the pipe by a plug or valve raised by means of a wire. This is much the more objectionable plan: for, in the interval between the times of use, the pipe, not being occupied by water, becomes filled with foul air which has ascended from the closet; and, when the plug or valve within the cistern is raised, water does not flow down the pipe till this stagnant air has bubbled up through the contents of the cistern. By either method there is risk of contamination of the water; and it seems unnecessary to insist that by the latter the pollution must be serious.

In large houses, having two, three, or more cisterns, sanitary arrangements are equally overlooked; and the cistern on the kitchen-floor, from which water is drawn for cooking and drinking purposes, too often supplies the servants' watercloset. The only way of accounting for the perpetuation of such mischievous arrangements is by supposing that as yet public attention has not been sufficiently directed to the importance of keeping water pure, and that the temptation to save a few feet of leaden pipe is too strong for builders, who are incredulous of the risks incurred. It cannot be too strongly urged that in every house not supplied by "constant service" there should be one cistern specially set aside for the water to be used for drinking and cooking purposes. And with regard to its regulation three other points are to be carefully observed:-

(1) The waste-pipe must not in any way communicate with the drains, else it may be the means of admitting foul air into the cistern, if not also into the house. Yet it will be found that at the present day builders often follow the dangerous practice of connecting the water-pipe with the soil-pipe or sewer, to which it acts as a ventilating shaft, so that the water in the cistern freely absorbs the sewer emanations and becomes polluted.

(2) There must be a well-fitting cover, in order to protect the surface of the water from the organic and inorganic particles which are constantly floating in the atmosphere, more especially in that of the basement story.

(3) At regular intervals the water must be entirely drawn off, so that the interior of the cistern may be thoroughly cleansed. In the case of a leaden cistern care must be taken to wash and cleanse the interior without scrubbing or scratching the surface of the metal. The most frequent cause of lead-poisoning is the use of water kept in leaden cisterns; $*$ but when water acts chemically on lead, the surface of the metal soon acquires a closely adhering hard Fragments of Science, article "Dust and Disease," 1871; Lectures on the Principles and Practice of Physic, by Sir Thomas Watson, Bart., M.D.,
F.R.S., vol. ii., pp. 583-601, 5th edit., 1871; Epidemic and Specifie ConF.R.S., vol. ii., pp. 583-601, 5th edit., 1871 ; Epidemic and Specific Con-
tagious Diseases-Considerations as to their Nature and Mode of Origin, by tagious Diseases-Concider
H. C. Bastian, M.D., F.R.S.

While the present paper is passing through the press, Sir Thomas Watson has written a letter to the Pall Mall Gazette, in reference to the illness of the Prince of Wales, in which the question of the genesis of enterie fever is thus clealy stated:- "Many believe that the poison which, issuing from sewers and cesspools, produces enteric fever, is capable of being generated de novo by the decomposition of fecal and other impurities, and that the poison of typhus fever may be, and is sometimes, created by the mere crowd ing together of human beings, especially when these are badly fed and live in close, filthy, and ill-ventilated places. On the other hand, many-of
whom I am one-have convinced themselves that serer gases never cause enteric fever except when they are impregnated with a specific poison, which has been thrown off from the body of some person sick of the same dise se; and that when typhus fever makes its appearance in the crowded dwellings of the poor, it is always because there was present in the otherwise foul and depressing atmosphere of those d wellings some leaven of contagium similarly derived from a subject or aubjects of that disorder. In short, that these two specific fevers resemble small-pox, scarlet fever,
measles, and the other diseases belonging to the same family, in this as in measles, and the other diseases belonging to the same family, in this as in
other particulars, that they never arise, nowadays, de novo, and indepenother particulars, that they never arise, nowadays, de novo, and indepen-
dently of pre-existing contagion. Of all of them it is alike true that the dently of pre-existing contagion. Of all of them it is alike true that the ouree of the infection may often elude the most diligent seareh for it."
* Cases like those which occurred at claremont among the members of the household of the ex-Royal Family of France are not rare. The effects were due to the use of water which had become impregnated by lead in the proportion of one grain to the imperial gallon. The children of the family did not suffer, but thirteen out of thirty-eight persons were affected to such a degree that the nails acquired a bluish discoloration. The children
of the family did not suffer. (Vide Dublin Quarterly Journal, May, 1849 also Medical Gazette, vol. sliv., p. 260.) 
white deposit, which prevents further chemical action of the water on the lead beneath. Still, as lead is an accumulative poison, which affects some persons strongly in the smallest quantities, and as the slightest degree of leadcontamination of water must be baneful to health, there can be no doubt that slate cisterns are to be recommended.*

It is true that we must still be, to some extent, at the mercy of the water companies. But let each man be roused to deal with that which is within his own control. The master of every household may protect himself and his family from such dangers as are liable to arise within his dwelling, and are none the less real because they are usually unrecognised-dangers which creep in at the cistern, and nestle in the dust which lies on the surface of the uncovered water.

There is no wish to play the alarmist, and there is really no ground for alarm. Cholera, choleraic diarrhœa, and enteric fever lose half their terrors, and more than half their dangers, when we have ascertained how they originate. Nothing can be more satisfactory than the knowledge that you may defy cholera so long as certain baneful particles are not introduced into your system. But this knowledge will afford poor consolation if it be found that from faulty cisterns you are liable to eat and drink the poison, and so obtain the disorder from any individual affected with it. $\dagger$

Although atmospheric conditions alone cannot generate cholera unless the specific exciting poison be present, and although the converse of this may also be true, still it cannot be doubted that even when no epidemic is abroad the water we drink may contain impurities prejuricial to health. And if, under ordinary circumstances, the majority of those who drink the tainted water escape unhurt, it only shows that some persons are made ill more readily than others.

Whether or not the cholera is coming should matter little. The man who would aroid panic must deliberately close every probable opening for attack. Forewarned he will be forearmed. And if the cholera do not come, he will at all events be defended from other minor diseases which are always at hand. Let us hope that his house is supplied by the water company from uncontaminated fountains bursting out in the chalk, or welling up in the gravel. Then let him not abuse this inestimable blessing of pure water by receiving it into ill-constructed cisterns, by allowing it to stagnate from neglect, or by omitting to cover and protect it from dust and dirt.

November, 1871.

\section{COD-LIVER OIL IN WHOOPING-COUGH.}

\section{BY J. PRESTWICH, L.R.C.P. \&c.}

From time to time we see various methods of treating whooping-cough advocated; but no remedy can be prescribed with certainty until the pathology of the disease is more perfectly known. In this paper it is not my intention to discuss the many theories of pathologists or to promulgate any new theory of my own, but simply to report a few cases selected from more than thirty in my own practice, in order to show the value of cod-liver oil in this peculiar complaint, so fatal to infant life, or, if not fatal, so distressing to children and parents. The action of any remedy which produces benefit equal to that which I have experienced with this valuable agent ought to be widely circulated amongst the profession. The improvement following the use of cod-liver oil in my own practice has been such that for some time I have considered it as a specific for whooping cough. As is well known, the spasmodic attacks of this complaint are almost always preceded for some days by in

* Some natural waters are prevented from attacking lead by the salts they hold in solution. The more nearly pure, or the more free from saline mater pp. 458.61; Taylor on Poisons, 2nd edit., pp. 506-7; and Taylor's Medical Jp. 458-61; Taylor on Poisons,

Jurisprudence, $1865, \mathrm{pp}$. $24,0-13$ ). "It cannot be too distinetly understood that the person who contracts holera in this country is ipso facto demonstrated with almost absolute certainty to have been exposed to excremental pollution. Excrementsodden earth, excrement-reeking air, excrement-tainted water-these are for us the causes of cholera." (Vide "Ninth Report of the Sanitary State of Privy Council.)
Hammatory or catarrhal symptoms. During this stage it has been my usual practice to treat all cases as ordinary attacks of catarrh, and afterwards to administer the oil. A fact worthy of notice is, that the majority of children had considerable enlargement of the concatenate glands; and the consequent reduction in the size of these glands may account to some extent for the benefit derived. It is also a remarkable circumstance that not one death has occurred where the oil has been administered and has been retained on the stomach.

CASE 1. - E. G-, aged nine months; male; a poor anæmic child, first seen Oct. 29 th, 1869 . Had had cough for ten days, with distinct whoop; paroxysms every hour, both night and day; was feverish; tongue furred and dry; pulse quick; respiration frequent, evidencing bronchitis. After pursuing the ordinary treatment until Nov. 13th, without any abatement of the cough, and the child being weak and emaciated, I ordered cod-liver oil, half a fluid drachm, four times a day. On the 14th, as he could not retain the ordinary oil, he was ordered Fox's "palatable cod-liver oil," one fluid drachm, every four hours. On Dec. 7 th he was convalescent.

CASE 2.-M. H-, female, aged eight months, was seen Nov. 20th, 1869. Whooping-cough came on every two hours during the night, and nearly as often in the day. Vomiting occurred after each paroxysm. Tongue clean. She was ordered to take a fluid drachm of Fox's cod-liver oil every four hours. On Dec. 6th she was nearly well. The patient was not seen afterwards.

CASE 3 (which deserves special attention). - G. Smale, aged four years. Had had cough for nine months, which came on every hour in the night, and six or eight times in the day, the paroxysms being severe, with scanty expectoration. He was thin, pale, and emaciated. Lobelia and chloral hydrate with syrup of white poppies was prescribed until Nov. 25th, with very little improvement, the paroxysms being as frequent as before. Two drachms of Fox's cod-liver oil were administered every four hours. On Dec. 5th the cough was almost gone, and there was no whoop; he was fuller in body, and was improving rapidly. On the 20 th the patient was convalescent.

The above are three specimen cases taken from a list of thirty-three to whom Fox's " palatable" cod-liver oil was given because of its singularly easy retention on the stomach. Some patients did not experience the same marked improvement as those reported, but all obtained decided relief. Now the question arises-Is the improvement to be attributed solely to the beneficial action of cod-liver oil, or has Fox's preparation a peculiar influence over the disease, besides its suitability to the palate? I shall be glad to have the opinion of other practitioners on this point.

Oldham, Aug. 21st, 1871.

\section{NOTE ON THE}

\section{DIGESTION OF MINERAL SUBSTANCES.}

BY RICHARD V. TUSON, F.C.S.,

PROFESSOR OF CHEMISTRY IN THE ROYAI VETERINARY COLLEGE.

Phrsiologists and chemists have hitherto entertained the belief that the principal if not the sole function of the pepsin and acid contained in the gastric juice is to render soluble the albuminoid constituents of food, and thus prepare them for the subsequent process of absorption.

Conceiving, however, that it would be extremely interesting to study the effect, if any, of the solvent constituents of the gastric juice upon mineral substances, especially those employed as medicines, I have set myself the task of investigating this subject. The inquiry is yet but in its infancy; nevertheless the results already obtained are suffciently positive and striking to induce me to "claim date" by placing on record the following experiments :-

Experiment 1.-A mixture of calomel* and distilled water containing 2 per cent of hydrochloric acid.

Experiment 2.-A mixture of calomel, pepsin, $t$ and distilled water.

Experiment 3.-A mixture of calomel, pepsin, and distilled water containing 2 per cent. of hydrochloric acid.

* The calomel employed in all the experiments was previously tested as to its purity.

$t$ Pepsina porci, prepared by Messrs. Bullock and Reynolds. 